\title{
Baseline impedance via manometry and ambulatory reflux testing are not equivalent when utilized in the evaluation of potential extra-esophageal gastroesophageal reflux disease
}

\author{
Thomas A. Zikos, George Triadafilopoulos, Afrin Kamal, Alexander Podboy, Irene S. Sonu, \\ Kirsten A. Regalia, Monica C. Nandwani, Linda A. Nguyen, Nielsen Q. Fernandez-Becker, John O. Clarke \\ Stanford Esophageal Multidimensional Program in Innovation and Research Excellence (SEMPIRE), Division of Gastroenterology and Hepatology, \\ Stanford University School of Medicine, Stanford, CA, USA \\ Contributions: (I) Conception and design: TA Zikos, JO Clarke; (II) Administrative support: TA Zikos, JO Clarke; (III) Provision of study materials \\ or patients: All authors; (IV) Collection and assembly of data: TA Zikos, JO Clarke; (V) Data analysis and interpretation: TA Zikos, JO Clarke; (VI) \\ Manuscript writing: All authors; (VII) Final approval of manuscript: All authors. \\ Correspondence to: John O. Clarke, MD. Division of Gastroenterology \& Hepatology, Stanford University School of Medicine, 430 Broadway Street, \\ Pavilion C, $3^{\text {rd }}$ Floor, MC: 6341, Redwood City, CA 94063, USA. Email: john.clarke@stanford.edu.
}

Background: Esophageal baseline impedance (BI) shows promise for the diagnosis of gastroesophageal reflux disease (GERD), but means of acquisition and relevance to extra-esophageal manifestations of GERD (EE-GERD) remain unclear. In this study we aim to (I) evaluate concordance between BI as measured by 24-hour pH-impedance (pH-MII) and high-resolution impedance manometry (HRIM), and (II) assess relationship to potential EE-GERD symptoms.

Methods: In this prospective open cohort study, patients presenting for outpatient HRIM and pH-MII studies were prospectively enrolled. All patients completed the GERD-HRQL, NOSE, and respiratory symptom index questionnaire (RSI), plus questions regarding wheezing and dental procedures. HRIM and $\mathrm{pH}-\mathrm{MII}$ were evaluated with calculation of BI. Correlations were assessed using either Pearson's correlation or Spearman's rank coefficients.

Results: 70 HRIM patients were enrolled, 35 of whom underwent pH-MII. There was no correlation between BI measurements as assessed by HRIM and $\mathrm{pH}-\mathrm{MII}$ proximally, but there was moderate-weak correlation distally ( $\mathrm{r}=0.34$ to 0.5 ). Distal acid exposure time correlated with distal BI only for measurements by $\mathrm{pH}-\mathrm{MII}$ (rho= -0.5 to -0.65 ), and not by HRIM. There was no relationship between proximal acid exposure time and proximal BI. There were no correlations when comparing proximal or distal BI measurements, acid exposure times, and impedance events to symptoms.

Conclusions: Concordance between BI as measured by HRIM and $\mathrm{pH}-\mathrm{MII}$ is poor, especially proximally, suggesting that these two methods are not interchangeable. There is no correlation between BI both distally/ proximally and symptoms of either GERD/EE-GERD, suggesting that many symptoms are unrelated to acid or that BI is not an adequate marker to assess EE-GERD symptoms.

Keywords: Baseline impedance (BI); gastroesophageal reflux (GERD); extra-esophageal reflux; impedance, manometry

Submitted Apr 09, 2020. Accepted for publication Sep 02, 2020.

doi: $10.21037 /$ jtd-20-1623

View this article at: http://dx.doi.org/10.21037/jtd-20-1623 


\section{Introduction}

The diagnostic evaluation and management of potential extra-esophageal manifestations of gastroesophageal reflux disease (EE-GERD), including laryngopharyngeal reflux (LPR), continues to be a dilemma for clinicians and researchers alike. In one community survey, around half of patients complained of laryngeal symptoms (1), but the etiology of these symptoms is often difficult to establish. Although the underlying etiologies are likely multifactorial, acid reflux is often implicated. The 2006 Montreal classification recognized cough, laryngitis, asthma, and dental erosions as established associations, with reflux, and pharyngitis, sinusitis, pulmonary fibrosis, and otitis media as possible associations (2). Since many of these symptoms are nonspecific and common, patients are often presumed to be suffering from EE-GERD when presenting with these symptoms and gastroenterologists today are faced with how best to diagnose and manage them. There have been multiple testing modalities proposed to diagnose those EEGERD symptoms that may be related to reflux, particularly LPR. These include pharyngeal $\mathrm{pH}$ testing (3), esophageal $\mathrm{pH}$ testing $(4,5)$, questionnaires $(5,6)$, direct laryngoscopy $(7,8)$, and salivary pepsin (9). Unfortunately, all these testing modalities are imperfect, and they often lack specificity

There has been recent interest in the use of baseline impedance (BI) (resistance to electrical conductivity of the esophagus unrelated to reflux episodes) as another modality to diagnose gastroesophageal reflux disease (GERD). Low esophageal BI has been proposed as a marker of esophageal damage, which can result from acid reflux, among other insults. Esophageal injury results in increased intercellular permeability, as seen on electron microscopy, leading to increased fluid and electrolyte flow, and reduced BI $(10,11)$. Assessment of BI has been found to be helpful in the evaluation of GERD using multiple modalities, including 24 hour $\mathrm{pH} /$ impedance testing $(\mathrm{pH}-\mathrm{MII})(4,12,13)$, high resolution impedance manometry (HRIM) (14), and the use of a dedicated mucosal impedance probe during endoscopy $(15,16)$.

Current BI testing has mostly focused on distal impedance in the context of GERD, EoE and control subjects, with limited evaluation of potential EE-GERD in the context of altered proximal impedance. Moreover, BI has been measured using several modalities and it is unclear how interchangeable these different modalities are. Since we face questions about both EE-GERD and the utilization of BI in our practice, we hypothesized to evaluate both (I) the concordance of BI values as measured by $\mathrm{pH}-\mathrm{MII}$ and HRIM at multiple esophageal levels, and (II) the relationship between BI at different levels throughout the esophagus and potential EE-GERD, as measured by symptom analysis and proximal reflux monitoring. We present the following article in accordance with the Strengthening the Reporting of Observational Studies in Epidemiology (STROBE) Statement reporting checklist (Available at http://dx.doi.org/10.21037/jtd-20-1623).

\section{Methods}

\section{Study population}

All patients presenting for $\mathrm{pH}-\mathrm{MII}$ ( $\mathrm{pH}-\mathrm{MII})$ and/or highresolution impedance manometry (HRIM) at our tertiary academic medical center were invited to participate, regardless of symptom burden. Patients were recruited from July to December 2017. Patients were asked to fill out questionnaires prior to catheter placement. Specifically, patients responded to the GERD health-related quality of life questionnaire (GERD-HRQL) (17), respiratory symptom index questionnaire (RSI) $(5,6)$, and the nasal obstruction symptom evaluation questionnaire (NOSE) (18), all of which have been previously validated. Questionnaires were scored according to standard procedures, and total scores were used in the final analysis as opposed to individual symptoms scores. Patients also responded to non-validated questions about wheezing and number of dental procedures in the last 2 years. Basic demographic information was collected about patients by reviewing their charts. The study was conducted in accordance with the Declaration of Helsinki (as revised in 2013). The study was approved by institutional review board of Stanford University (IRB-41412) and informed consent was taken from all the patients.

\section{HRIM and pH-MII testing}

HRIM testing was performed in a standard fashion. A highresolution esophageal manometry/impedance catheter with 36 manometry sensors and 18 impedance sensors (Medtronic, Sunnyvale, California) was passed transnasally and positioned in the stomach such that at least 2 gastric sensors were present. Images were acquired in the supine position, utilizing a standard protocol of $5 \mathrm{ml}$ swallows. An experienced motility specialist read all studies utilizing the Chicago Classification (CC), version 3 - and 
each study was re-evaluated by the study investigators. Any discrepancies were reviewed for consensus. The BI was calculated afterwards by the study investigators by capturing a minimum 15 -second resting period interval and then exporting the impedance data to a spreadsheet (Excel, Microsoft, Redmond, USA) for manual calculations to obtain the mean impedance at each sensor level over the course of the extracted rest period. A period for analysis was selected which showed good bolus clearance at all levels of the esophagus without any associated swallows. We used a similar method as described by Ravi and colleagues from the Mayo Clinic (14).

With respect to $\mathrm{pH}-\mathrm{MII}$, standard protocols again were used for data acquisition. Catheters were placed by blind passage after the HRIM was complete, such that the distal $\mathrm{pH}$ sensor was placed $5 \mathrm{~cm}$ proximal to the proximal margin of the lower esophageal sphincter (LES). Recording of events and symptoms continued for 24 hours. For this study, dual $\mathrm{pH} /$ impedance probes were utilized in all patients such that a probe was placed in both the distal and proximal esophagus. A combination of VersaFlex ${ }^{\circledR}$ LPR ZNID15 and $19 \mathrm{~cm}$ catheters were used depending on patient size (Medtronic, Sunnyvale, California). The distal $\mathrm{pH}$ probe was placed at $5 \mathrm{~cm}$, and the proximal $\mathrm{pH}$ probe placed either 15 or $19 \mathrm{~cm}$ above depending on the catheter - chosen at the time of placement by the motility nurse upon review of the manometry and evaluation of esophageal length. The locations of the impedance sensors were as follows (in relation to the lower $\mathrm{pH}$ probe): VersaFlex $19 \mathrm{~cm}(-3,-1,1,10,12,14,17,20 \mathrm{~cm})$; VersaFlex $15 \mathrm{~cm}$ $(-3,-1,1,3,5,12,14,16 \mathrm{~cm})$. An experienced motility provider read the studies-and all studies were re-reviewed by study investigators. Mean Nocturnal Baseline Impedance (MNBI) was determined afterwards as outlined in the Porto consensus (4). Using RapidReader (Medtronic, Sunnyvale, USA), three $10 \mathrm{~min}$ intervals during the hours of $1 \mathrm{AM}, 2 \mathrm{AM}$, and $3 \mathrm{AM}$ free from refluxes or swallows were analyzed, and data was extracted to Excel (Microsoft, Redmond, USA) for more detailed analysis. MNBI values at an individual level were averaged across these time intervals. Some impedance locations were located either within or above the upper esophageal sphincter (UES). These were eliminated from analysis and reported as missing data when relevant.

\section{Outcomes}

The primary outcome was to assess correlation between
BI assessed by HRIM and $\mathrm{pH}-\mathrm{MII}$ at various levels of the esophagus. The secondary outcomes of the study were as follows: (I) assess correlation of $\mathrm{pH}$ readings to $\mathrm{MI}$ assessed by both HRIM and pH-MII, (II) assess correlation of symptoms to MI assessed by both HRIM and $\mathrm{pH}-\mathrm{MII}$, and (III) assess correlations among symptom assessed by questionnaires. Sample size was calculated based on the primary outcome using Fisher's z-test for correlation. To detect a moderate correlation $(\mathrm{r}=0.5)$ with alpha $=0.05$ and beta $=0.8$ a sample size of 30 would be needed.

\section{Statistical analysis}

All correlations were assessed with either linear regression (Pearson's correlation coefficient, r), Spearman's rank correlation (rho), or logistic regression (odds-ratios), depending on the type and distribution of the data. The data were not corrected for multiple comparisons, so it is important to take this into consideration during analysis. BI values were compared to values at other positions using a repeated measures ANOVA with Huynh-Feldt corrected P values. Given the smaller sample size, scope, and exploratory nature of the study, sensitivity analyses and exploration of confounders and effect modification was not done. Missing data were eliminated from applicable analyses. Sensitivity analyses were done for outcome 2 above, stratifying by PPI usage and esophageal motility abnormalities, in attempt to control for the potential influence on symptoms. Data analysis was completed with Stata version 13.1 (StataCorp, College Station, Texas).

\section{Results}

\section{Baseline demographics}

Ninety patients filled out the questionnaires, 70 patients had HRIM completed (20 failed placement or other technical issues occurred), and 35 patients had both HRIM and pH-MII completed (Table 1). Of those 70 with completed HRIM, 49.3\% had a CCv.3 classified motility disorder whereas the remainder of the studies were normal per CCv3. Of the 35 patients with pH-MII testing, 34.3\% had a borderline or abnormal distal $\mathrm{pH}$ acid exposure time $(>4 \%$ and $>6 \%$ proposed as a cutoff for borderline and pathological distal reflux, respectively) $(4,19)$, while only $11.4 \%$ had a proximal $\mathrm{pH}$ acid exposure time $>1 \%$ (proposed as a cutoff for pathological proximal reflux) (5). A $\mathrm{pH}$ of $<4$ was considered pathological for all studies. 
Table 1 Basic demographics

\begin{tabular}{|c|c|}
\hline Variables & Data \\
\hline \multicolumn{2}{|l|}{ Demographics $(n=90)$} \\
\hline Age, years (mean $\pm S D)$ & $51.6 \pm 17.6$ \\
\hline Female & $50 \%$ \\
\hline \multicolumn{2}{|l|}{ Race/ethnicity } \\
\hline White & $63.3 \%$ \\
\hline Black & $4.4 \%$ \\
\hline Hispanic (any race) & $12.2 \%$ \\
\hline Asian & $11.1 \%$ \\
\hline Other & $8.8 \%$ \\
\hline BMI (mean \pm SD) & $25.8 \pm 5.44$ \\
\hline Asthma/COPD & $10.6 \%$ \\
\hline Lung transplant & $7.1 \%$ \\
\hline Allergic rhinitis & $11.7 \%$ \\
\hline Ever smoker & $21.4 \%$ \\
\hline Prior ear, nose or throat surgery & $29.4 \%$ \\
\hline Prior esophageal surgeries/procedures & $21.2 \%$ \\
\hline Opioid use & $5.9 \%$ \\
\hline \multicolumn{2}{|l|}{ Survey results $(n=90)$} \\
\hline $\begin{array}{l}\text { Respiratory symptom index questionnaire } \\
\text { (RSI) (mean } \pm \text { SD) }\end{array}$ & $16.1 \pm 10.0$ \\
\hline $\mathrm{RSI}>13$ & $55.6 \%$ \\
\hline NOSE (mean \pm SD) & $26.5 \pm 24.6$ \\
\hline
\end{tabular}

Table 1 (continued)

Despite the relatively low number of patients with proximal acid exposure, $55.2 \%$ of the total patients had an RSI $>13$ (proposed as a diagnostic cutoff for LPR) $(5,6)$, which represents a disconnect between proximal acid exposure and symptoms (Table 1).

\section{BI assessed by HRIM and pH-MII}

In general, the assessments of BI by HRMI $v s$. pH-MII yielded different results. Mean impedance values were generally higher as assessed by $\mathrm{pH}-\mathrm{MII}$, compared to HRIM (Figures 1,2). Additionally, there was a proximaldistal BI gradient (with proximal impedance values being higher) for patients assessed by MII, but not present for
Table 1 (continued)

\begin{tabular}{lc}
\hline Variables & Data \\
\hline GERD-HRQL (mean \pm SD) & $16.2 \pm 11.7$ \\
Report of wheezing & $30.3 \%$ \\
Dental procedures in last 2 years (median, & $1(0-3)$ \\
IQR) & \\
Impedance manometry results ( $\mathrm{n}=70)$ & \\
Study done on PPI & $35.1 \%$ \\
Achalasia & $4.0 \%$ \\
Esophago-gastric junction outflow & $28.0 \%$ \\
obstruction (EGJOO) & \\
Jackhammer esophagus & $5.3 \%$ \\
Distal esophageal spasm (DES) & $5.3 \%$ \\
Absent contractility & $2.7 \%$ \\
Ineffective esophageal motility (IEM) & $13.3 \%$ \\
Normal motility & $50.7 \%$ \\
pH study results ( $=35)$ & \\
Study done on proton pump inhibitor (PPI) & $17.1 \%$ \\
Distal pH acid exposure (median, IQR) & $1.5 \%(0.5-6.9 \%)$ \\
Distal pH exposure $>4 \%$ & $34.3 \%$ \\
Proximal Ph acid exposure (median, IQR) & $0 \%(0-0.2 \%)$ \\
Proximal Ph exposure $>1 \%$ & $11.4 \%$ \\
Proximal Ph >1\% & $10.7 \%$ \\
RSI >13 & $55.2 \%$ \\
\hline
\end{tabular}

patients assessed by HRIM (Figure 1). The correlation between distal BI as assessed by HRIM and MII was moderate to poor, ranging from $\mathrm{r}=0.5$ to $\mathrm{r}=0.34(\mathrm{P}=0.006$ and $\mathrm{P}=0.05$ respectively), but was statistically significant (Figure 2). There was no correlation between proximal BI as assessed by HRIM and MII (Figure 2).

Correlation of acid exposure to BI assessed by HRIM and $\mathrm{pH}-\mathrm{MII}$ : Distal acid exposure time percentage (AET $\%)$ correlated negatively with $\mathrm{BI}$ as assessed by $\mathrm{MII}$ at both $1-3 \mathrm{~cm}(\mathrm{rho}=-0.65, \mathrm{P}<0.001)$, and $3.1-5 \mathrm{~cm}(\mathrm{rho}=-0.50$, $\mathrm{P}=0.002$ ) above the LES. This relationship was not significant for HRIM, though the trend was in the same direction. For proximal sensors $(1-3 \mathrm{~cm}$ and $3.1-5 \mathrm{~cm}$ below the UES), there was no correlation between AET 

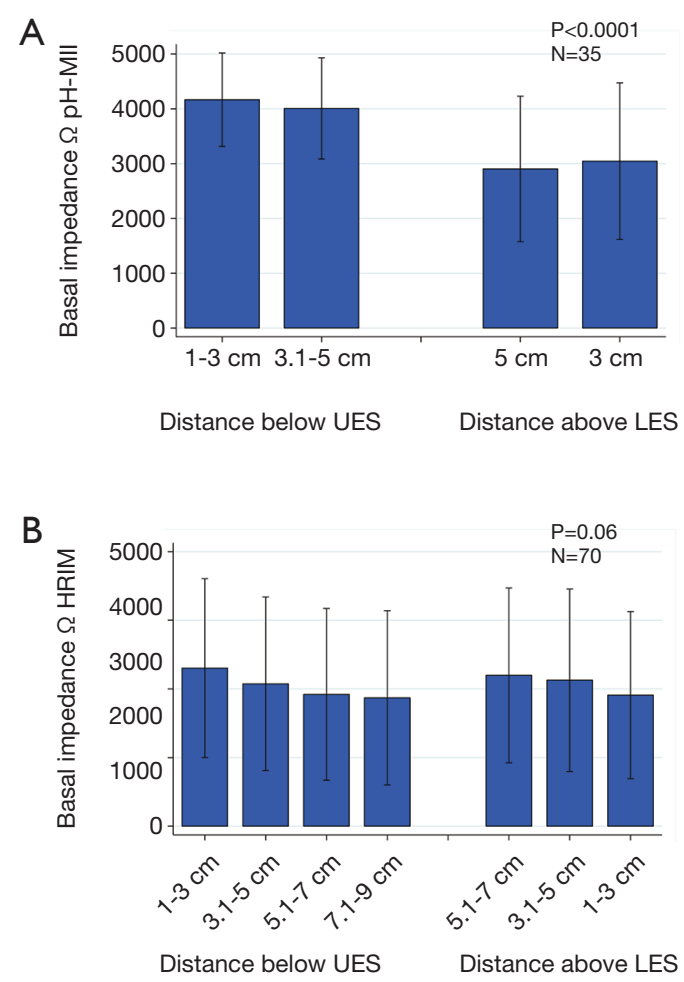

Figure 1 Basal impedance (BI) values as recorded by $\mathrm{pH}-\mathrm{MII}$ and HRIM. Mean basal impedance values, \pm standard deviation, are displayed, as measured by both 24 hour $\mathrm{pH} / \mathrm{impedance}$ ( $\mathrm{pH}-\mathrm{MII}$ ) and high resolution impedance manometry (HRIM). Values are displayed in terms of distance from either the upper esophageal sphincter (UES) or lower esophageal sphincter (LES). Repeated measures ANOVA was used to determine if there were differences among basal impedance values at different levels of the esophagus. Huynh-Feldt corrected $\mathrm{P}$ values are displayed on the graphs along with sample size (n).

and BI (Figure 3).

\section{Correlation of EE-GERD symptoms with acid exposure and impedance events}

There was no correlation when comparing distal AET \%, proximal AET \%, total impedance events, and proximal impedance to symptoms of EE-GERD (GERD-HRQL, RSI, NOSE, patient reported wheezing, patient reported dental procedure in the last 2 years) (Table S1). There was one statistically significant correlation between the NOSE questionnaire and total impedance events $(\mathrm{rho}=-0.41$, $\mathrm{P}=0.015$ ), but this likely represents error from multiple statistical testing, given the modest correlation and $\mathrm{P}$ value. The relation also runs in the opposite direction of what would be expected. There was a small cohort of patients who had proximal acid exposure $>1 \%$ ( 4 of 35 patients). When looking specifically at this small cohort of patients with high proximal acid exposure, they did not have statistically different questionnaire scores than patients with low acid exposure (data not shown). The overall results were similar when stratified by PPI use prior to testing, and presence or absence of a Chicago Classification 3.0 abnormality (data not shown).

\section{Correlation of BI to EE-GERD symptoms}

There was no correlation when comparing BI, as assessed by HRIM and pH-MII, to symptoms of EE-GERD (GERD-HRQL, RSI, NOSE, patient-reported wheezing, patient-reported dental procedure in the last 2 years) (Tables S2,S3). There were 4 comparisons that were statistically significant, all with $\mathrm{P}$ values $0.03-0.05$, which are likely spurious given the multiple statistical comparisons. These correlations are also in the opposite direction of what would be expected (as we would hypothetically expect lower BI associated with more symptoms with the hypothesis that acid-mediated symptoms would result in a lower BI recording). The overall results were similar when stratified by PPI use prior to testing, and presence or absence of a Chicago Classification 3.0 abnormality (data not shown).

\section{Correlation among questionnaires}

There was moderate correlation among the RSI, NOSE, and GERD-HRQL surveys (GERD-HRQL vs. RSI, $r=0.47$, $\mathrm{P}<0.0001$; RSI vs. NOSE, $\mathrm{r}=0.63, \mathrm{P}<0.0001$; GERDHRQL vs. NOSE, $\mathrm{r}=0.27, \mathrm{P}=0.013$ ) (Figure 4). A higher GERD-HRQL score was also moderately predictive of the presence of wheezing (odds-ratio 1.11, $\mathrm{P}<0.001$ ), but not predictive of the number of dental procedures in the last 2 years (Figure 4).

\section{Discussion}

Reliable testing for the diagnosis of EE-GERD remains a clinical challenge. Our study evaluates the utility of esophageal BI for diagnosis. The use of BI offers a theoretical advantage over standard $\mathrm{pH}-\mathrm{MII}$ testing as it assesses underlying damage to the esophageal mucosa, as opposed to measuring only events on the day of recording (20). 


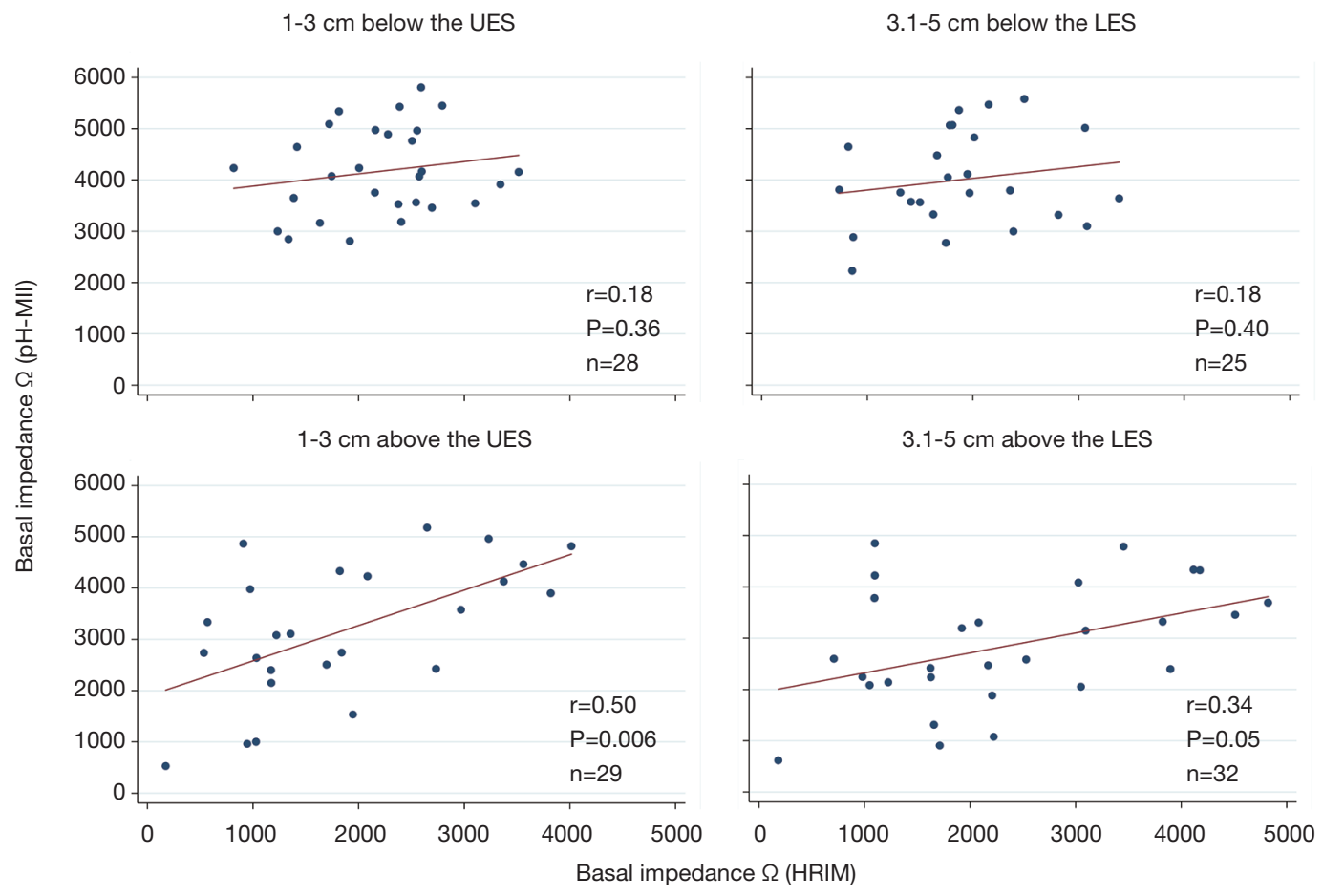

Figure 2 Correlation of basal impedance values between pH-MII and HRIM. All values were compared using linear regression at different levels of the esophagus as displayed. Correlation coefficients (r), P values, and sample size (n) are displayed on the graphs. Abbreviations: lower esophageal sphincter (LES), upper esophageal sphincter (UES), $24 \mathrm{hr} \mathrm{pH} /$ impedance (pH-MII), high resolution impedance manometry (HRIM).

The use of BI in GERD has been evaluated by several studies using several methods, including $\mathrm{pH}$-MII (4,12,13,21-23), HRIM (14,24), and directed mucosal probes during endoscopy $(15,16,25)$. The optimal method of such assessment remains unclear. Our study is the first to our knowledge to evaluate the relationship of proximal impedance to $\mathrm{pH}-\mathrm{MII}$ and HRIM, and to evaluate symptom correlation to proximal BI values.

Perhaps the key finding in our study was that we found poor correlation between BI as measured by $\mathrm{pH}-\mathrm{MII}$ and HRIM-suggesting that these two technologies may not be equally meritorious. In the 2 distal esophageal probes correlation coefficients (r) ranged from 0.34 to 0.5 . Another study evaluating this correlation distally found slightly better correlations but still suboptimal with correlation coefficients (r) of 0.59 (14). On the other hand, our study found no correlations proximally (Figure 3). BI has gotten significant attention recently as a means to assess mucosal integrity. Vaezi and colleagues have pioneered an endoscopic mucosal impedance probe and have shown now in several key studies that this can segregate patients with GERD and eosinophilic esophagitis from controls $(15,16,25,26)$; BI measured via ambulatory reflux testing has been championed by investigators in Italy (13,21-23) and has significant appeal in that it may provide similar information while utilizing existing equipment. However, ambulatory reflux testing can be cumbersome and uncomfortable for patients, leading to recent investigation into whether this same data can be obtained via stationary manometryimpedance studies. Data from Ravi and colleagues at the Mayo Clinic have been encouraging and suggest that BI measured via manometry-impedance and 24-hour $\mathrm{pH}$ impedance testing correlates $(14,27)$; however, our findings are in contrast and show poor correlation only in the distal esophagus - and no correlation in the proximal esophagus. Granted, many of the patients in our series had esophageal dysmotility and that may have contributed to these findings. Nevertheless, we would argue that MNBI as measured via 24-hour $\mathrm{pH}$-impedance testing is not synonymous with BI as measured by manometry. 


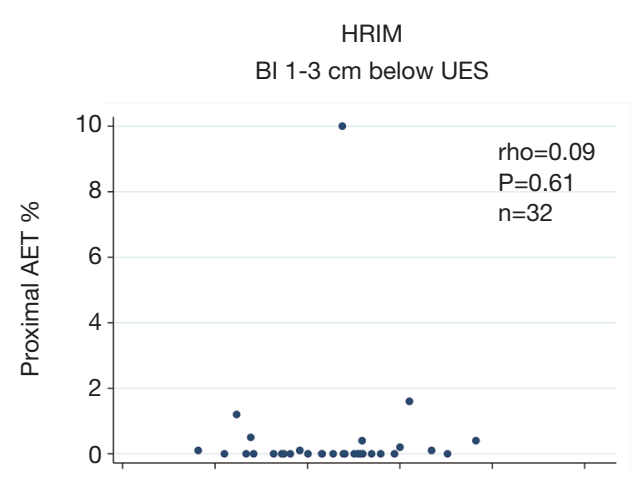

BI $3.1-5 \mathrm{~cm}$ below UES

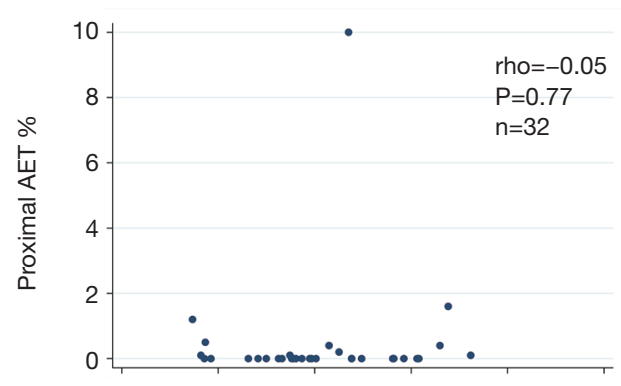

BI 5.1-7 cm above LES

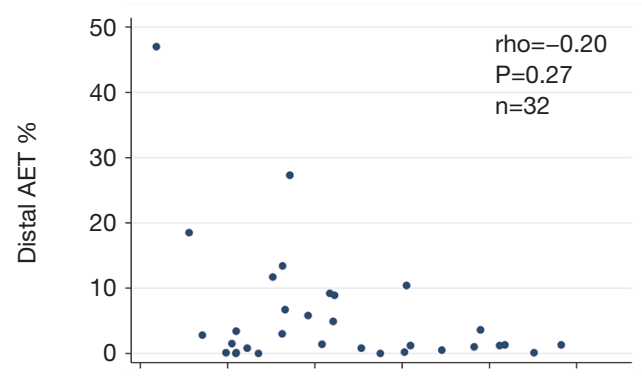

BI 1-3 cm above LES

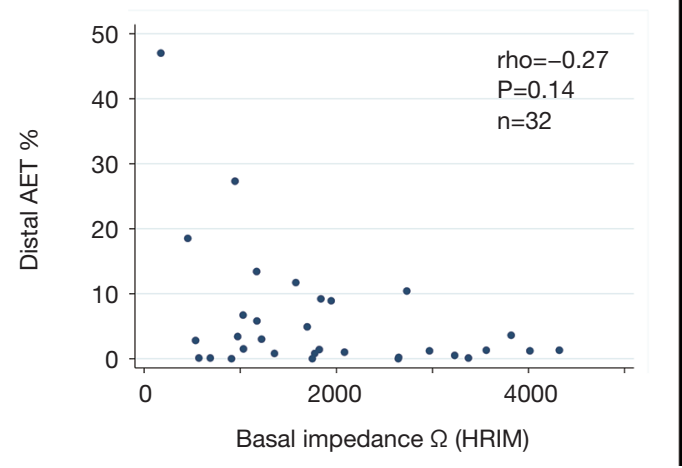

MII

BI 1-3 cm below UES

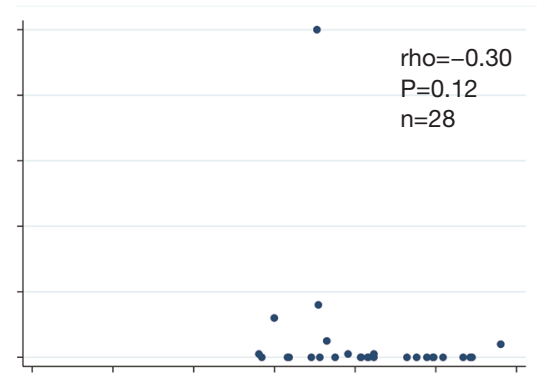

BI 3.1-5 cm below UES

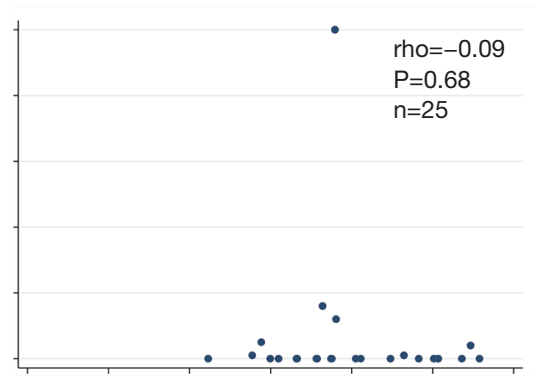

BI $5 \mathrm{~cm}$ above LES

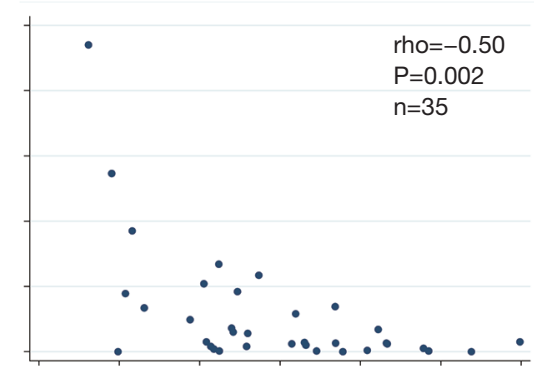

BI $3 \mathrm{~cm}$ above LES

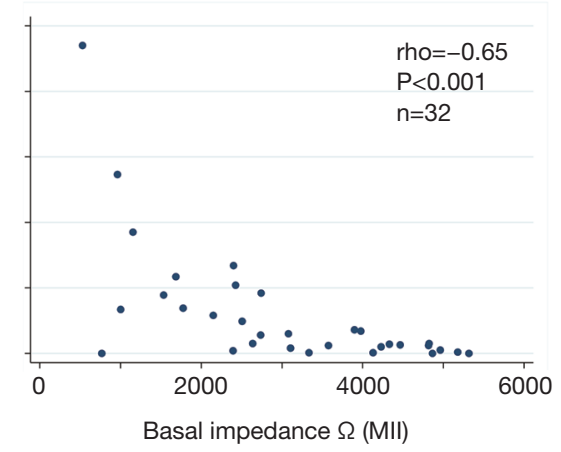

Figure 3 Correlation of acid exposure time percentage to basal impedance using both HRIM and pH-MII. Total acid exposure time percentage (AET \%) using distal and proximal probes was compared with basal impedance (BI) in the distal and proximal esophagus (at locations indicated above the graphs) using spearman's rank correlation. This was done separately for basal impedance values assessed by high resolution impedance manometry (HRIM) and $24 \mathrm{hr} \mathrm{pH} /$ impedance (MII). Correlation coefficients (rho), P values, and sample size (n) are displayed on the graphs. 

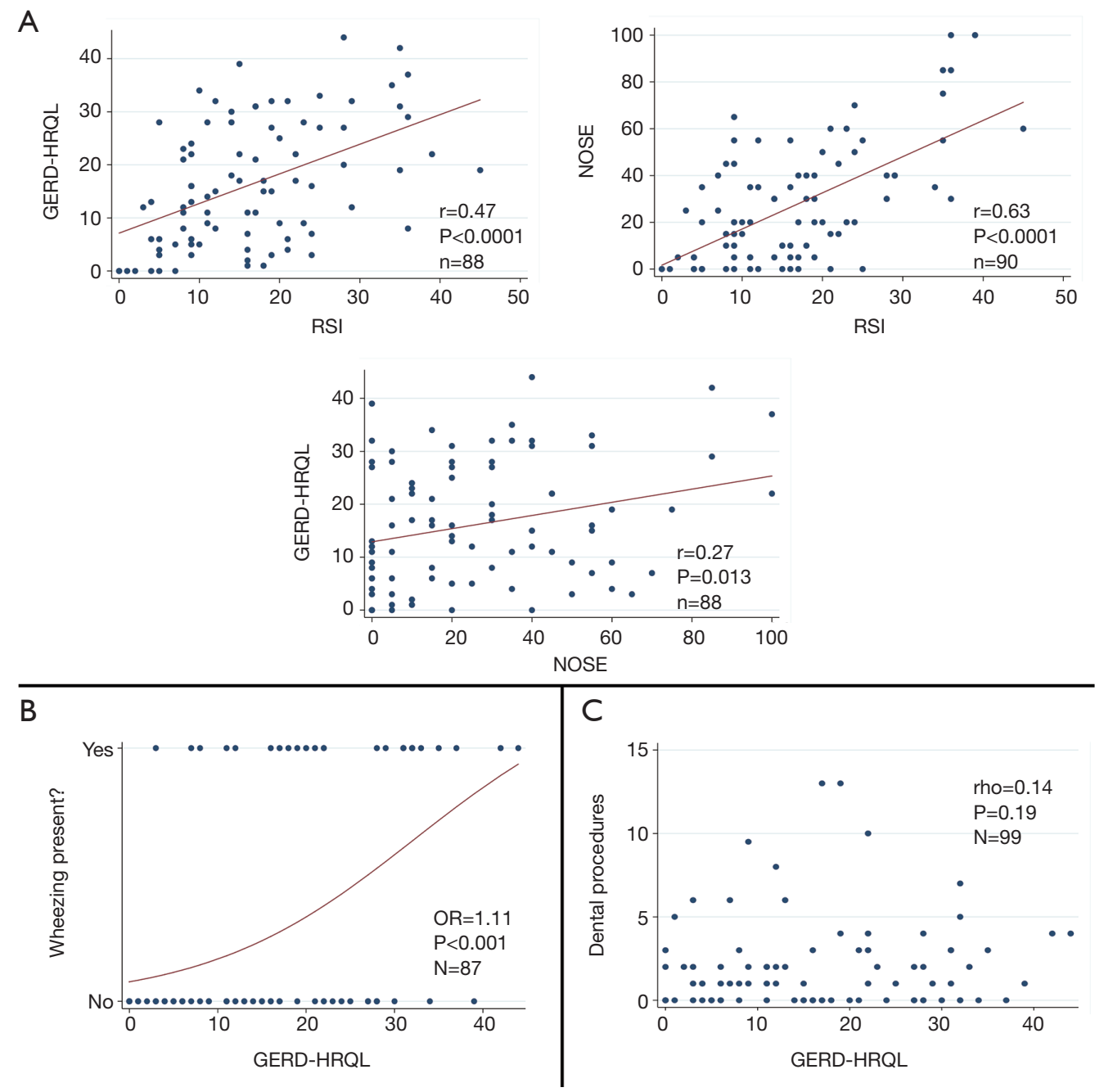

Figure 4 Correlation among potential extra-esophageal symptoms of reflux. Panel A compares the GERD-HRQL, NOSE, and RSI questionnaire results using Pearson's linear regression. Linear trend lines are displayed, as well as P values, correlation coefficients (r), and sample size (n). Panel B compares patient-reported wheezing (as a binary variable) to the GERD-HRQL questionnaire results using logistic regression. A logistic trend line is displayed, as well as the odds-ratio (OR), P value, and sample size (n). Panel C compares patientreported number of dental procedures in the last 2 years to the GERD-HRQL questionnaire. Given the non-normal distribution of dental procedures, Spearman's rank correlation was used. The correlation coefficient (rho), P value, and sample size (n) are displayed.

In addition, correlation of distal BI to distal acid exposure was better when evaluated by $\mathrm{pH}-\mathrm{MII}$ as opposed to HRIM, suggesting that $\mathrm{pH}-\mathrm{MII}$ may be a better corollary to acid exposure. Correlation coefficients (rho) ranged from -0.5 to -0.65 in the distal probes, which is similar to the range reported in the literature ( $r=-0.45$ to -0.7$)(12,13,28)$. Proximally, there was no correlation between basal impedance and acid exposure (Figure 4). To some extent this is not surprising, as BI measured via 24-hour $\mathrm{pH}-\mathrm{MII}$ takes an average recording over a 30 -minute period encompassing three 10-minute blocks at three consecutive hours-whereas $\mathrm{BI}$ as measured by HRIM takes a single resting period with only approximately 15-30 seconds of evaluation. Given the vagaries involved in BI, including positioning and timing/number of recent swallows, it is not surprising that $\mathrm{BI}$ as measured by $\mathrm{pH}-\mathrm{MII}$ is more reproducible-likely because it is more accurate. This may be especially the case in subjects with underlying esophageal dysmotility. That being said, while not surprising, this is a bit disappointing, as acquisition of $\mathrm{BI}$ in a single resting frame during HRIM 
would certainly be an easier parameter to obtain than the more cumbersome nocturnal $\mathrm{pH}-\mathrm{MII}$ MNBI calculation.

Our study also evaluated the relationship of GERDHRQL, NOSE, RSI, patient-reported wheezing, and dental procedures to BI measurements as assessed by HRIM and $\mathrm{pH}-\mathrm{MII}$. Taken together, there was no correlation between BI, both proximally and distally to symptoms (Tables $S 2, S 3$ ). Additionally, there was no correlation between acid exposure and impedance events to symptom questionnaires (Table S1). There were a few $\mathrm{P}$ values that were just below 0.05 , but with correlations in the opposite direction of what would be expected. We do not believe there is any clinical significance to these and we believe that they likely resulted from repeated testing and statistical bias. We did speculate that perhaps our finding of mildly higher impedance parameters in the proximal esophagus of symptomatic patients could be potentially explained by increased swallowing/air clearance related to some combination of hypervigilance, increased swallowing and reflux-induced swallowing; however, we feel it is more likely that this finding is simply a confounder of multiple analysis paradigms, especially as it goes against the direction of our original hypothesis.

There are several limitations that need to be acknowledged. To begin with, our study was performed in symptomatic patients undergoing motility evaluation at a tertiary hospital; as such, approximately half had a formal motility disorder that may have led to lower rates of impedance correlation. It is certainly possible that correlation between $\mathrm{BI}$ as measured by manometry and MNBI as measured by $\mathrm{pH}$-impedance would have been significantly stronger if only patients with normal motility were evaluated. Likewise, BI correlation with symptoms may have been more present if our study population was more homogeneous, as mechanisms of esophageal symptomatology may clearly differ between different defined esophageal disorders. Second, while 90 subjects were enrolled in the study, only 35 subjects underwent both HRIM and pH-impedance testing concurrently, and of those 35 patients there were a very small number who had abnormal proximal esophageal acid exposure (only 4 patients). Thus, our study was not powered to make conclusive statements with regards to EE-GERD symptom correlation as fewer than expected patients had true EE-GERD when one uses proximal esophageal acid exposure as the gold standard. Finally, the patients underwent evaluation on the regimen recommended by their treating gastroenterologist, and as such there was a mixture of patients on and off PPI therapy at the time of testing. As PPI therapy clearly affects acid exposure time, and subsequently BI, this is also a confounding factor. Nevertheless, we believe that these findings likely represent real-world experience, and may be more applicable to a busy clinical esophageal practice than a more narrowlydefined experience.

In conclusion, our study shows overall poor correlation between BI assessed by pH-MII and HRIM. This suggests that the different methods of basal impedance measurements are not equivalent, and more study will be needed to determine the optimal measurement technique. BI values as measured by HRIM and $\mathrm{pH}-\mathrm{MII}$ do not appear to be interchangeable, and we suspect that the one obtained by $\mathrm{pH}-\mathrm{MII}$ is likely the more reliable for the reasons detailed above. The mucosal probe pioneered by Vaezi and colleagues offers significant promise in this arena and is likely an even better measure of BI than the values obtained through transnasal catheters; however, we did not have access to that probe for our investigation. We did not find correlation of BI, regular impedance events, or acid exposure to symptoms at any level of the esophagus. This suggests that many potential symptoms of EE-GERD likely have other etiologies independent of acid, or less likely, that BI (as measured by HRIM or pH-MII) is not an adequate modality to evaluate the effects of acid exposure/injury in the proximal esophagus.

\section{Acknowledgments}

Funding: None.

\section{Footnote}

Reporting Checklist: The authors have completed the STROBE reporting checklist. Available at http://dx.doi. org/10.21037/jtd-20-1623

Data Sharing Statement: Available at http://dx.doi. org/10.21037/jtd-20-1623

Conflicts of Interest: All authors have completed the ICMJE uniform disclosure form (available at http://dx.doi. org/10.21037/jtd-20-1623). JOC serves as an unpaid editorial board member of Fournal of Thoracic Disease from Oct 2019 - Sep 2021. The other authors have no conflicts of interest to declare.

Ethical Statement: The authors are accountable for all 
aspects of the work in ensuring that questions related to the accuracy or integrity of any part of the work are appropriately investigated and resolved. The study was conducted in accordance with the Declaration of Helsinki (as revised in 2013). The study was approved by institutional review board of Stanford University (IRB-41412) and informed consent was taken from all the patients.

Open Access Statement: This is an Open Access article distributed in accordance with the Creative Commons Attribution-NonCommercial-NoDerivs 4.0 International License (CC BY-NC-ND 4.0), which permits the noncommercial replication and distribution of the article with the strict proviso that no changes or edits are made and the original work is properly cited (including links to both the formal publication through the relevant DOI and the license). See: https://creativecommons.org/licenses/by-nc-nd/4.0/.

\section{References}

1. Connor NP, Palazzi-Churas KL, Cohen SB, et al. Symptoms of extraesophageal reflux in a communitydwelling sample. J Voice 2007;21:189-202.

2. Vakil N, van Zanten SV, Kahrilas P, et al. The Montreal definition and classification of gastroesophageal reflux disease: a global evidence-based consensus. Am J Gastroenterol 2006;101:1900-20; quiz 1943.

3. Friedman M, Hamilton C, Samuelson CG, et al. The value of routine $\mathrm{pH}$ monitoring in the diagnosis and treatment of laryngopharyngeal reflux. Otolaryngol Head Neck Surg 2012;146:952-8.

4. Roman S, Gyawali CP, Savarino E, et al. Ambulatory reflux monitoring for diagnosis of gastro-esophageal reflux disease: Update of the Porto consensus and recommendations from an international consensus group. Neurogastroenterol Motil 2017;29:1-15.

5. Ford CN. Evaluation and management of laryngopharyngeal reflux. JAMA 2005;294:1534-40.

6. Belafsky PC, Postma GN, Koufman JA. Validity and reliability of the reflux symptom index (RSI). J Voice 2002;16:274-7.

7. Hicks DM, Ours TM, Abelson TI, et al. The prevalence of hypopharynx findings associated with gastroesophageal reflux in normal volunteers. J Voice 2002;16:564-79.

8. Vavricka SR, Storck CA, Wildi SM, et al. Limited diagnostic value of laryngopharyngeal lesions in patients with gastroesophageal reflux during routine upper gastrointestinal endoscopy. Am J Gastroenterol
2007;102:716-22.

9. Calvo-Henríquez C, Ruano-Ravina A, Vaamonde P, et al. Is Pepsin a Reliable Marker of Laryngopharyngeal Reflux? A Systematic Review. Otolaryngol Head Neck Surg 2017;157:385-91.

10. Tobey NA, Carson JL, Alkiek RA, et al. Dilated intercellular spaces: a morphological feature of acid reflux-damaged human esophageal epithelium. Gastroenterology 1996;111:1200-5.

11. Caviglia R, Ribolsi M, Maggiano N, et al. Dilated intercellular spaces of esophageal epithelium in nonerosive reflux disease patients with physiological esophageal acid exposure. Am J Gastroenterol 2005;100:543-8.

12. Kessing BF, Bredenoord AJ, Weijenborg PW, et al. Esophageal acid exposure decreases intraluminal baseline impedance levels. Am J Gastroenterol 2011;106:2093-7.

13. Martinucci I, de Bortoli N, Savarino E, et al. Esophageal baseline impedance levels in patients with pathophysiological characteristics of functional heartburn. Neurogastroenterol Motil 2014;26:546-55.

14. Ravi K, Geno DM, Vela MF, et al. Baseline impedance measured during high-resolution esophageal impedance manometry reliably discriminates GERD patients. Neurogastroenterol Motil 2017. doi: 10.1111/nmo.12974.

15. Ates F, Yuksel ES, Higginbotham T, et al. Mucosal impedance discriminates GERD from non-GERD conditions. Gastroenterology 2015;148:334-43.

16. Patel DA, Higginbotham T, Slaughter JC, et al. Development and Validation of a Mucosal Impedance Contour Analysis System to Distinguish Esophageal Disorders. Gastroenterology 2019;156:1617-26.e1.

17. Velanovich V. The development of the GERDHRQL symptom severity instrument. Dis Esophagus 2007;20:130-4.

18. Stewart MG, Witsell DL, Smith TL, et al. Development and validation of the Nasal Obstruction Symptom Evaluation (NOSE) scale. Otolaryngol Head Neck Surg 2004;130:157-63.

19. Gyawali CP, Kahrilas PJ, Savarino E, et al. Modern diagnosis of GERD: the Lyon Consensus. Gut 2018;67:1351-62.

20. Lacy BE, Weiser K, Chertoff J, et al. The diagnosis of gastroesophageal reflux disease. Am J Med 2010;123:583-92.

21. Frazzoni L, Frazzoni M, de Bortoli N, et al. Postreflux swallow-induced peristaltic wave index and nocturnal baseline impedance can link PPI-responsive heartburn to reflux better than acid exposure time. Neurogastroenterol 
Motil 2017. doi: 10.1111/nmo.13116. Epub 2017 May 25.

22. Frazzoni M, Savarino E, de Bortoli N, et al. Analyses of the Post-reflux Swallow-induced Peristaltic Wave Index and Nocturnal Baseline Impedance Parameters Increase the Diagnostic Yield of Impedance-pH Monitoring of Patients With Reflux Disease. Clin Gastroenterol Hepatol 2016;14:40-6.

23. Rengarajan A, Savarino E, Della Coletta M, et al. Mean Nocturnal Baseline Impedance Correlates With Symptom Outcome When Acid Exposure Time Is Inconclusive on Esophageal Reflux Monitoring. Clin Gastroenterol Hepatol 2020;18:589-95.

24. Hung JS, Wong MW, Liu TT, et al. Evaluation of Baseline Impedance During Water-perfused High Resolution Impedance Manometry in Patients With Symptomatic GERD. J Clin Gastroenterol 2019;53:350-4.

25. Saritas Yuksel E, Higginbotham T, Slaughter JC, et al. Use of direct, endoscopic-guided measurements of mucosal impedance in diagnosis of gastroesophageal reflux disease. Clin Gastroenterol Hepatol 2012;10:1110-6.

26. Katzka DA, Ravi K, Geno DM, et al. Endoscopic Mucosal Impedance Measurements Correlate With Eosinophilia and Dilation of Intercellular Spaces in Patients With Eosinophilic Esophagitis. Clin Gastroenterol Hepatol 2015;13:1242-8.e1.

27. Halland M, Ravi K, Nelson HA, et al. Baseline Impedance Measured During High-resolution Esophageal Impedance Manometry in Patients With Rumination Syndrome is as Abnormal as in Patients With GERD. J Clin Gastroenterol 2020;54:28-34.

28. Kandulski A, Weigt J, Caro C, et al. Esophageal intraluminal baseline impedance differentiates gastroesophageal reflux disease from functional heartburn. Clin Gastroenterol Hepatol 2015;13:1075-81.
Cite this article as: Zikos TA, Triadafilopoulos G, Kamal A, Podboy A, Sonu IS, Regalia KA, Nandwani MC, Nguyen LA, Fernandez-Becker NQ, Clarke JO. Baseline impedance via manometry and ambulatory reflux testing are not equivalent when utilized in the evaluation of potential extra-esophageal gastroesophageal reflux disease. J Thorac Dis 2020;12(10):56285638. doi: /10.21037/jtd-20-1623 


\section{Supplementary}

Table S1 Relationship between extra-esophageal manifestations of GERD and 24-h pH and impedance events

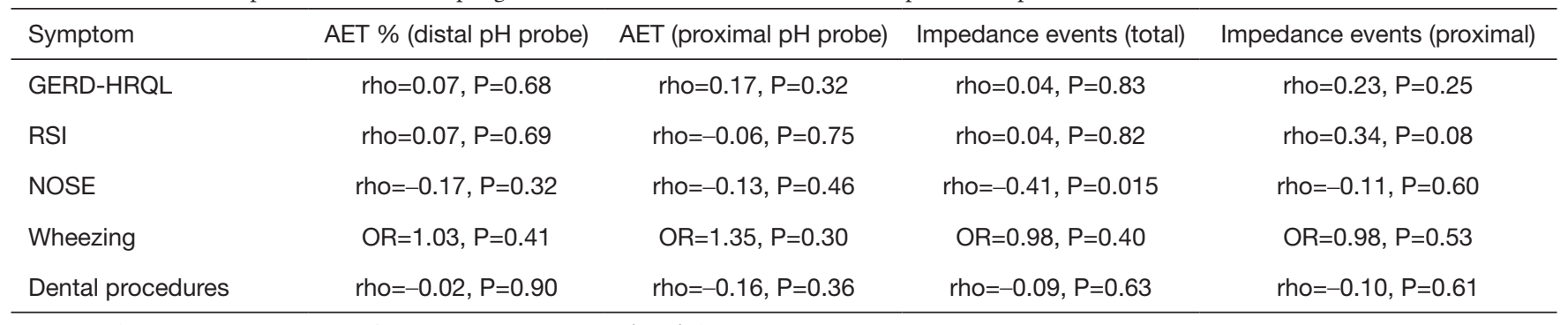

Twenty-four-hour ambulatory \% acid exposure times (AET) from both the distal and proximal pH probes, as well as total and proximal impedance events were assessed as independent variables, and, in turn, were all compared to dependent variables of GERD-HRQL, RSI, and NOSE questionnaire scores, as well as patient reported wheezing and number of dental procedures in the last 2 years. Relationships were assessed with either Spearman's rank correlation (rho) or logistic regression [odds-ratios (OR)]. P values are displayed in the table.

Table S2 Relationship between extra-esophageal manifestations of GERD and BI assessed by HRIM

\begin{tabular}{lcccccc}
\hline Sensor measuring basal impedance & GERD-HRQL & RSI & NOSE & Wheezing & Dental Procedures \\
\hline $1-3 \mathrm{~cm}$, distal to UES & $r=0.08, P=0.50$ & $r=0.18, P=0.14$ & $r=0.16, P=0.19$ & $O R=1.00, P=0.90$ & $r h o=0.13, P=0.30$ \\
$3.1-5 \mathrm{~cm}$, distal to UES & $r=0.04, P=0.71$ & $r=0.17, P=0.15$ & $r=0.04, P=0.76$ & $O R=1.00, P=0.85 \quad r h o=0.08, P=0.50$ \\
$5.1-7 \mathrm{~cm}$, distal to UES & $r=0.09, P=0.47$ & $r=0.25, P=0.04$ & $r=0.04, P=0.74$ & $O R=1.00, P=0.65 \quad r h o=0.13, P=0.27$ \\
$7.1-9 \mathrm{~cm}$, distal to UES & $r=0.15, P=0.21$ & $r=0.26, P=0.03$ & $r=0.07, P=0.56$ & $O R=1.00, P=0.58 \quad r h o=0.11, P=0.35$ \\
$5.1-7 \mathrm{~cm}$, proximal to LES & $r=-0.04, P=0.77$ & $r=0.25, P=0.03$ & $r=0.09, P=0.43$ & $O R=1.00, P=0.70 \quad r h o=0.07, P=0.55$ \\
$3.1-5 \mathrm{~cm}$, proximal to LES & $r=-0.11, P=0.38$ & $r=0.19, P=0.11$ & $r=0.09, P=0.44$ & $O R=1.00, P=0.82 \quad r h o=0.00, P=0.98$ \\
$1-3 \mathrm{~cm}$, proximal to LES & $r=-0.10, P=0.40$ & $r=0.19, P=0.11$ & $r=0.09, P=0.45$ & $O R=1.00, P=0.64 \quad r h o=-0.01, P=0.91$ \\
\hline
\end{tabular}

$\mathrm{BI}$ was compared to GERD-HRQL, RSI, and NOSE questionnaire scores, as well as patient-reported wheezing and number of dental procedures in the last 2 years. Correlation was assessed with either linear regression ( $r$ ), Spearman's rank correlation (rho), or logistic regression [odds-ratios (OR)]. $\mathrm{P}$ values are displayed in the table.

Table S3 Relationship between extra-esophageal manifestations of GERD and basal impedance assessed by pH-MII

\begin{tabular}{lccccc}
\hline Sensor measuring basal impedance & GERD-HRQL & RSI & NOSE & Wheezing & Dental Procedures \\
\hline $1-3 \mathrm{~cm}$, distal to UES & $r=-0.17, P=0.40$ & $r=-0.18, P=0.36$ & $r=0.36, P=0.06$ & $O R=1.00, P=0.42$ & $r h o=-0.08, P=0.68$ \\
$3.1-5 \mathrm{~cm}$, distal to UES & $r=-0.19, P=0.37$ & $r=0.15, P=0.47$ & $r=0.40, P=0.05$ & $O R=1.00, P=0.83 \quad r h o=0.22, P=0.29$ \\
$3 \mathrm{~cm}$, proximal to LES & $r=-0.17, P=0.32$ & $r=-0.20, P=0.25$ & $r=-0.07, P=0.69$ & $O R=1.00, P=0.90$ & $r h o=0.12, P=0.50$ \\
$5 \mathrm{~cm}$, proximal to LES & $r=-0.11, P=0.55$ & $r=-0.06, P=0.73$ & $r=0.03, P=0.89$ & $O R=1.00, P=0.73 \quad r h o=0.15, P=0.42$ \\
\hline
\end{tabular}

$\mathrm{BI}$ was compared to GERD-HRQL, RSI, and NOSE questionnaire scores, as well as patient reported wheezing and number of dental procedures in the last 2 years. Correlation was assessed with either linear regression (r), Spearman's rank correlation (rho), or logistic regression [odds-ratios $(\mathrm{OR})]$. $\mathrm{P}$ values are displayed in the table. 